Check for updates

Cite this: RSC Adv., 2019, 9, 536

Received 4th November 2018

Accepted 28th November 2018

DOI: 10.1039/c8ra09122f

rsc.li/rsc-advances

\section{Rational design of efficient transition metal core- shell electrocatalysts for oxygen reduction and evolution reactions $\uparrow$}

\begin{abstract}
Zhenghang Zhao, (D) ${ }^{a}$ Jason D'Souza, ${ }^{a}$ Fuyi Chen (iD ${ }^{\mathrm{b}}$ and Zhenhai Xia*ab
Ag can form core-shell structures with other non-precious transition metals, which is a promising candidate as an efficient and cost-effective electrocatalyst to replace $\mathrm{Pt}$ and $\mathrm{RuO}_{2}$ for oxygen reduction and evolution reactions (ORR and OER) in fuel cells and metal-air batteries. In this paper, polyicosahedral ( $p l h) \mathrm{Ag}_{32} \mathrm{X}_{6}(\mathrm{X}=3 \mathrm{~d}$ transition metals) core-shell structures are calculated systematically by the density functional theory (DFT) method to predict their electrocatalytic activities for ORR and OER. It is found that the strain on the outer shell of the core-shell structures can be an intrinsic descriptor that describes the bifunctional catalytic activities of the catalysts. A higher compressive strain leads to more positive charge on the surface of the shell and consequently higher catalytic activities. The results provide a theoretical base for the rational design and screening of the Ag-based core-shell catalysts for clean energy conversion and storage.
\end{abstract}

\section{Introduction}

Fuel cells along with metal-air batteries are considered as nextgeneration clean energy technologies with numerous advantages such as being low cost, environment friendly, and easy to mass produce. These energy technologies can provide an optimal solution to clean and sustainable energy in combination with never-ending but intermittent natural sources such as wind power and solar energy. ${ }^{1}$ At the heart of the energy technologies, electrocatalysts are necessary to catalyze the critical chemical reactions, oxygen reduction reaction (ORR) and oxygen evolution reactions (OER) in fuel cells and metal-air batteries. Noble metals and their alloys (e.g., $\mathrm{Pt} / \mathrm{C}^{2}$ and $\left.\mathrm{RuO}_{2} / \mathrm{C}^{3}\right)$ are usually used as the catalysts in the energy devices. However, the noble metal catalysts are scarce and can lead to CO poisoning. To lower the cost and promote the commercialization of the clean energy technologies, extensive study has been made on a variety of materials including transition metals, metal oxides, carbon nanomaterials, and transition metal dichalcogenides. Some of these materials have exhibited high catalytic efficiency comparable to or better than the noble metal counterparts. $^{2-10}$

Among the materials, $\mathrm{Ag}$ and its alloys are stable and only $2 \%$ as expensive as platinum. Experimental results have shown that ${ }^{a}$ Department of Materials Science and Engineering, University of North Texas, Denton,
TX, 76201, USA. E-mail: Zhenhai.Xia@unt.edu
${ }^{b}$ School of Materials Science and Engineering, Northwestern Polytechnical University,
Xi'an 710072 , China

$\dagger$ Electronic supplementary information (ESI) available. See DOI: 10.1039/c8ra09122f
$\mathrm{Ag}$ holds a great potential as a bifunctional catalyst for fuel cells and metal-air batteries especially in alkaline environments. ${ }^{11-13}$ In particular, $\mathrm{Ag}-\mathrm{Cu}$ alloys or core-shell structures show better catalytic activities than the noble metals for ORR and OER. Nan et al. predicted from the first-principles calculations that the working potentials of pure $\mathrm{Ag}$, core-shell $\mathrm{Ag} / \mathrm{Ag}_{3} \mathrm{Cu}$ and alloy $\mathrm{Ag}_{3} \mathrm{Cu}$ were $0.737,0.761$ and $0.675 \mathrm{~V}$, respectively, indicating that the core-shell $\mathrm{Ag} / \mathrm{Ag}_{3} \mathrm{Cu}$ nanoparticles provide the highest working potential and the lowest overpotential, which is comparable to that of the $\mathrm{Pt}(111)$ facets. ${ }^{14}$ This prediction was confirmed by their experimental results. In these Ag-based structures, the transition metal $\mathrm{Cu}$ played an essential role in determining the electrochemical activities of the core-shell structures, similar to the alloys of platinum and early transition metals. ${ }^{15-18}$ Qaseem et al. summarized the silver core-shell structures for catalytic reactions such as $\mathrm{Ag}-\mathrm{Pd}, \mathrm{Ag}-\mathrm{Cu}, \mathrm{Ag}-\mathrm{Au}$ and $\mathrm{Ag}-\mathrm{Co}^{19}{ }^{19}$ Specifically, Ag-Pt catalyst exhibits three times better electrocatalytic performance than Pt. ${ }^{20,21}$ Simulation studies reveal that $\mathrm{Ag}_{x} \mathrm{Au}_{y}$ clusters enhance the adsorptions of CO and $\mathrm{O}_{2}$, and thus facilitate $\mathrm{O}_{2}$ dissociation and CO oxidation. ${ }^{22} \mathrm{Ag}-\mathrm{Pt}$ bimetallic nanoparticles are more stable than traditional $\mathrm{Pt} / \mathrm{C}$ cathode and it can catalyze methanol oxidation. ${ }^{23,24}$ Shin et al. did DFT study on Ag-Pt cluster for comprehensive catalytic analysis. ${ }^{25}$ Strasser $e t$ al. found Pt-rich nanoparticles have compress strain resulting in a shift of band structure, thus improves the catalysis of reactions like ORR ${ }^{26}$ Besides, Ag-Au cluster also shows higher catalytic activity than alloy and monometallic nanoparticles. ${ }^{27,28}$ Although the superior catalytic capabilities of the silver coreshell structures for ORR have been demonstrated theoretically and experimentally, the design principle for these structures is 
still underexplored. Establishing the design principle or descriptor that correlates core-shell structures to their catalytic activity will accelerate the search for highly efficient catalysts for clean energy conversion and storage.

In this paper, we performed the density functional theory calculations on various plh $\mathrm{Ag}_{32} \mathrm{X}_{6}$ and $\mathrm{Cu}_{32} \mathrm{X}_{6}$ core-shell metal structures ( $\mathrm{X}=3 \mathrm{~d}$ transition metals) including $\mathrm{Ag}_{32} \mathrm{Sc}_{6}, \mathrm{Ag}_{32} \mathrm{Ti}_{6}$, $\mathrm{Ag}_{32} \mathrm{~V}_{6}, \quad \mathrm{Ag}_{32} \mathrm{Cr}_{6}, \quad \mathrm{Ag}_{32} \mathrm{Mn}_{6}, \quad \mathrm{Ag}_{32} \mathrm{Fe}_{6}, \quad \mathrm{Ag}_{32} \mathrm{Co}_{6}, \quad \mathrm{Ag}_{32} \mathrm{Ni}_{6}$ and $\mathrm{Ag}_{32} \mathrm{Cu}_{6}$. The overpotentials of OER and ORR were calculated in order to evaluate the electrochemical activities of the core-shell structures. Based on the DFT results, a design strategy was proposed to predict the catalytic performances of the core-shell metal clusters.

\section{Computational details}

The computational calculation was performed by $a b$ initio within the framework of the density functional theory (DFT) as implemented in Vienna Ab-initio Simulation Package (VASP). $\mathrm{Ag}_{32} \mathrm{X}_{6}$ polyicosahedral ( $\mathrm{plh}$ ) core-shell structures were constructed as shown in Fig. 1, in which $\mathrm{X}$ represents the $3 \mathrm{~d}$ transitional metal (TM) elements ( $\mathrm{X}=\mathrm{Sc}, \mathrm{Ti}, \mathrm{V}, \mathrm{Cr}, \mathrm{Mn}, \mathrm{Fe}, \mathrm{Co}, \mathrm{Ni}$, $\mathrm{Cu}$ ) in the periodic table. $\mathrm{Ag}$ atoms covered the $\mathrm{X}$ atom core to form the plh core-shell cluster. Zhang et al. showed that polyicosahedral (plh) $\mathrm{Ag}_{32} \mathrm{Cu}_{6}$ core-shell structure was more stable than truncated octahedral (TO) $\mathrm{Ag}_{32} \mathrm{Cu}_{6}$ one. ${ }^{29}$ In order to perform the DFT calculations, we identified 4 unique positions on particle surface as active sites that were marked by numbers in Fig. 1. The size of the unit cell is $20 \AA \times 20 \AA \times 20 \AA$ with a bond length of $2.67 \AA$ between $\mathrm{Ag}$ and $\mathrm{X}$ atoms approximately. For DFT simulations, projector augmented wave (PAW) pseudopotential was utilized to demonstrate the correlation of valence electrons. ${ }^{30}$ Generalized gradient approximation (GGA) was introduced by Perdew, Burke, and Ernzerhof (PBE) to state the electronic exchange and interactions. ${ }^{31}$ Brillouin zone sampling at the $\Gamma$ point was used. An interatomic interaction in a Hartree-Fock like manner was used as the $\mathrm{PBE}+\mathrm{U}$ method to correctly describe the systems with localized d and f electrons, typically transition metals. ${ }^{19} U$ parameter was chosen based on previous calculations on bi-metallic structures. ${ }^{32,33}$ A cut-off energy of $480 \mathrm{eV}$ was set throughout the calculations and the self-convergence level was set to be $1 \times 10^{-5} \mathrm{eV}$ for electron relaxations. Ionic relaxation converged when the total force reached less than $0.01 \mathrm{eV} \AA^{-1}$. Entropy and zero-point energy were also considered by vibrational frequency at $300 \mathrm{~K}$. Bader charge analysis was conducted to evaluate the charge transfer within the nanoparticles. ${ }^{34,35}$

To carry out the calculations, two steps were conducted as lattice optimizations and electronic freedom re-optimized with no ions moved. After the $\mathrm{Ag}_{32} \mathrm{X}_{6}$ core-shell clusters were relaxed, we calculated the adsorption free energies of intermediates such as $\mathrm{O}, \mathrm{OH}, \mathrm{O}_{2}$ and $\mathrm{OOH}$ on the core-shell cluster to get free energies as well as overpotentials for ORR and OER. In this paper, both ORR and OER overpotentials were calculated to evaluate the bifunctionality of the structure for both reactions while the 4-electron transfer mechanism was believed to be the pathway for OER and ORR in fuel cells and metal-air batteries. The details regarding the overpotentials of OER, ORR can be found in various literatures such as Nørskov et al., ${ }^{2}$ Man et al., ${ }^{3}$ Zhao et al., ${ }^{, 36-39} \mathrm{Li}$, et al., ${ }^{4}$ and Zhang et al. ${ }^{\mathbf{4 , 4 0 - 4 2}}$ Further details about the DFT calculations are provided in the ESI. $\dagger$

\section{Results and discussion}

The catalytic reactions were studied on plh core-shell metal clusters as shown in Fig. 1. Four distinct active sites on the surface of the core-shell structures are labeled in Fig. 1(B). The bridge sites are not taken into consideration in this study because previous work has shown that these bridge sites are not stable for adsorptions of intermediates..$^{\mathbf{2 9 , 4 3}}$ There are two major types of mechanisms towards OER and ORR: 4-electron (4e) transfer mechanism with the final production of $\mathrm{H}_{2} \mathrm{O}$, and 2electron (2e) transfer mechanism featuring the production of $\mathrm{H}_{2} \mathrm{O}_{2}$. The elementary steps of these $4 \mathrm{e}$ and $2 \mathrm{e}$ transfer reactions are shown in Fig. $\mathrm{S} 1$ and $\mathrm{S} 2, \uparrow$ respectively.

Free energy diagrams of $\mathrm{Ag}_{32} \mathrm{X}_{6}$ and $\mathrm{Cu}_{32} \mathrm{X}_{6}$ structures for OER and ORR were plotted in Fig. 2(A) and (B), respectively. Among the core-shell structures studied in this study, $\mathrm{Ag}_{32} \mathrm{Cu}_{6}$
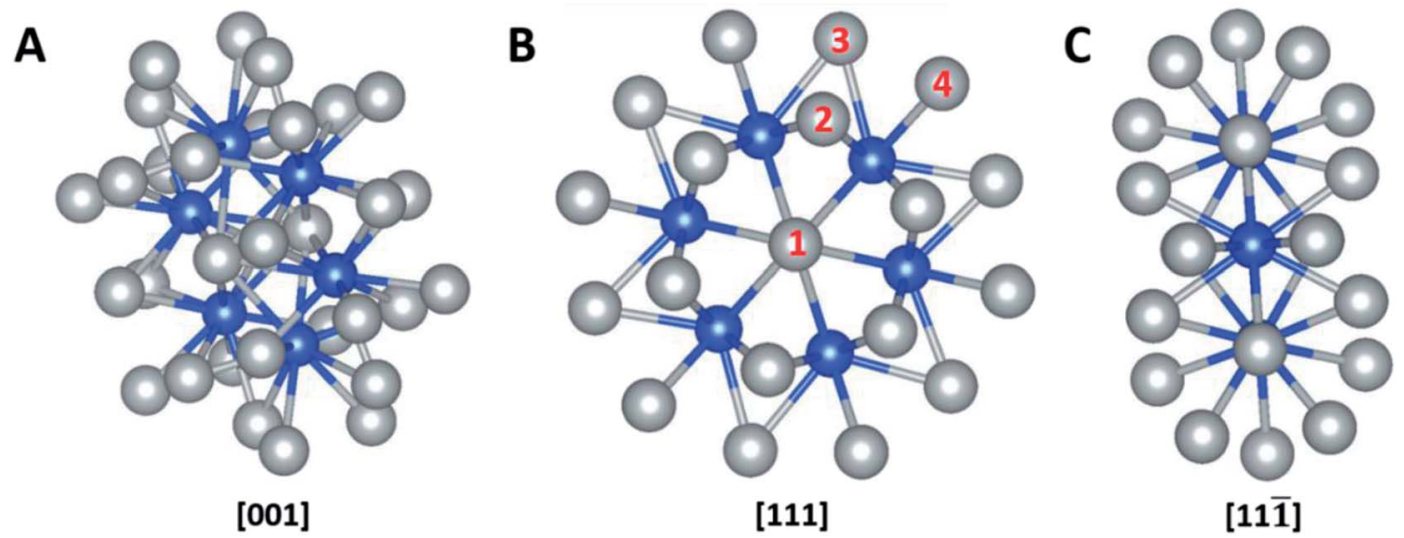

Fig. 1 Schematic models of $\mathrm{Ag}_{32} \mathrm{X}_{6}$ plh core-shell structure. (A), [001] view; (B), [111] view; (C), [111] view. Four distinct active sites are marked in (B). Color legend: grey $=$ shell elements, blue $=$ core elements. 

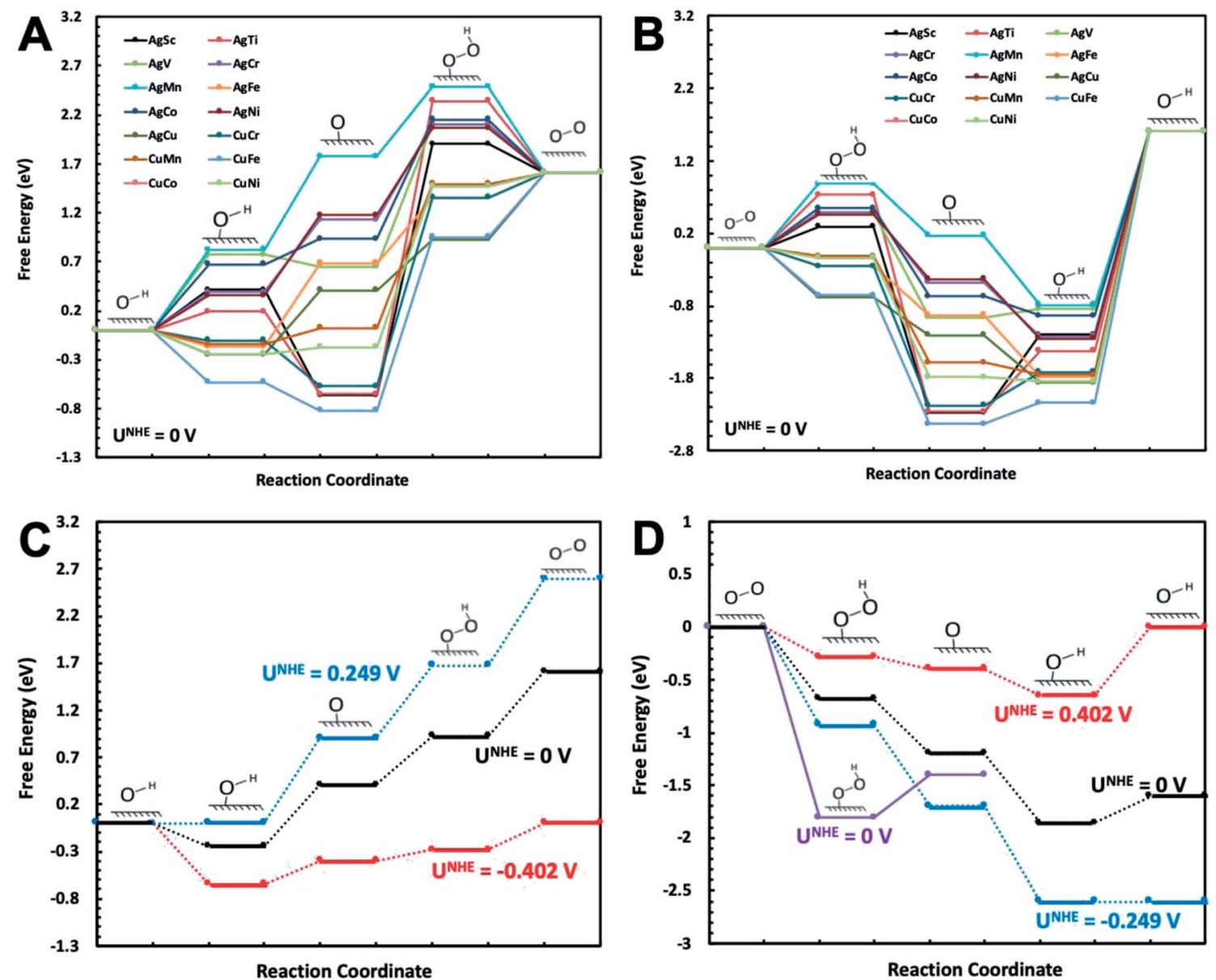

Fig. 2 Free energy diagram of $\mathrm{Ag}_{32} \mathrm{X}_{6}$ and $\mathrm{Cu}_{32} \mathrm{X}_{6}$ plh core-shell structures at zero potential $\left(U_{0}=0 \mathrm{~V}\right)$ for $(\mathrm{A})$ OER and $(\mathrm{B})$ ORR in 4 -electron transfer reaction mechanism in alkaline medium. Free energy diagram of $\mathrm{Ag}_{32} \mathrm{Cu}_{6}$ plh core-shell structure with the best catalytic performance at zero potential $\left(U_{0}=0 \mathrm{~V}\right)$, the equilibrium potential $\left(U_{0}=0.402 \mathrm{~V}\right)$, uphill/downhill potential $\left(U_{0}=0.249 \mathrm{~V}\right)$ for $(C)$ OER and (D) ORR in alkaline medium

plh core-shell structure showed the best catalytic activities for OER and ORR since it has the smallest overpotential (the applied voltage that makes the reaction free energy in all elementary steps just uphill or downhill for OER and ORR, respectively). As shown in Fig. 2(C) and (D) the free energies for the $\mathrm{Ag}_{32} \mathrm{Cu}_{6}$ plh core-shell structure are plotted for the electrode potential of $0 \mathrm{~V}, 0.23 \mathrm{~V}$ and $0.402 \mathrm{~V}$ (equilibrium voltage for each step in OER and ORR). We also found sites $3 \& 4$ on the $\mathrm{Ag}_{32} \mathrm{Cu}_{6}$ plh core-shell structures (Fig. 1(B)) have better electrochemical activities of ORR and OER than sites $1 \& 2 \mathrm{do}$. This is because sites $3 \& 4$ are outer-shell top sites while $1 \& 2$ are sort of bend inward, which may affect the adsorption of intermediates. The free energy diagram for 2-electron transfer mechanism was calculated and plotted in Fig. S3. $\dagger$ For comparison, the free energy of 2-electron transfer ORR mechanism of $\mathrm{Ag}_{32} \mathrm{Cu}_{6} \mathrm{plh}$ core-shell structure was also plotted in Fig. 2(D). For the 2electron transfer, the calculated electrode potential (overpotential) for $\mathrm{Ag}_{32} \mathrm{Cu}_{6}$ is $1.107 \mathrm{~V}$, which was far larger than that for 4-electron transfer mechanism, indicating 2-electron mechanism is not favorable for plh core-shell metal structures.

Overpotential is an indicator of catalytic activities for electrocatalysts, which is the extra energy required for a reaction than thermodynamically expected. To theoretically evaluate the electrocatalytic performance of the plh core-shell structures, the adsorption free energies of $\mathrm{O}^{*}, \mathrm{OH}^{*}, \mathrm{O}_{2}^{*}, \mathrm{OOH}^{*}$ (* refers to an active site on free surface) were calculated with the DFT method. Details regarding reaction equations, adsorption energies and overpotentials can be found in ESI. $\dagger$ We correlated the reaction free energy of $\mathrm{OH}^{*}$ formation $\left(\Delta G_{3}\right)$ with that of $\mathrm{O}^{*}$ formation $\left(\Delta G_{2}\right)$, as shown in Fig. 3(A). A linear regression was made with the linear least squares fitting technique and the fitting equation is $\Delta G_{3}=-\Delta G_{2}+1.7214$. When $\Delta G_{2}$ equals $\Delta G_{3}$, the overpotential will approach its lower limit that is $0.459 \mathrm{~V}$. This lower limit of the overpotential is comparable to $\mathrm{Pt} / \mathrm{C}$ for $\mathrm{ORR}^{2}$ and $\mathrm{RuO}_{2} / \mathrm{C}$ for OER, ${ }^{3}$ as well as Pt-free catalysts for ORR or OER such as N-doped graphene, ${ }^{9,10}$ indicating Ag plh coreshell clusters can be used as an effective bifunctional catalyst for ORR and OER in fuel cells and metal-air batteries.

To establish design rules that correlate core-shell structures to their catalytic activity, the overpotentials was plotted as a function of the descriptors $\Delta G_{\mathrm{O}^{*}}-\Delta G_{\mathrm{OH}^{*}}$ and $\Delta G_{\mathrm{OOH}^{*}}$. As shown in Fig. 3(B) and (C), OER overpotentials were drawn as a function of $\Delta G_{\mathrm{O}^{*}}-\Delta G_{\mathrm{OH}^{*}}$ while ORR overpotentials were plotted against $\Delta G_{\mathrm{OOH}^{*}}$. Both of the plots show "volcano" 

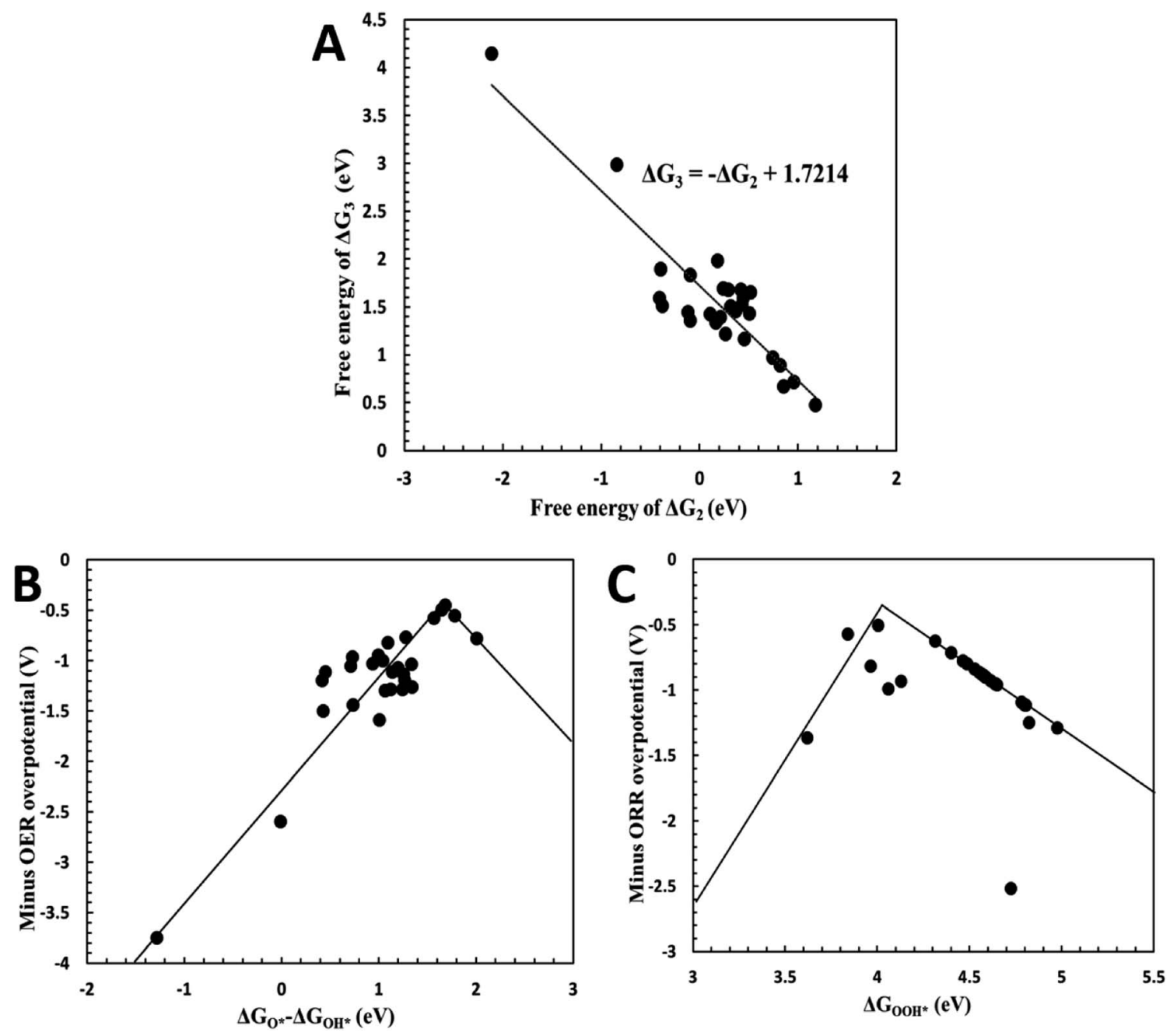

Fig. 3 (A) Linear fitting of reaction free energy $\Delta G_{3}$ and $\Delta G_{2}$; (B) minus OER overpotential as a function of descriptor $G_{\mathrm{O}^{*}}-\Delta G_{\mathrm{OH}}$; (C) minus $O R R$ overpotential as a function of descriptor $\Delta G_{\mathrm{OOH}^{*}}$.

relationships, on which the catalysts with the best performance are located at the summits of the volcanos. When $G_{\mathrm{O}^{*}}-\Delta G_{\mathrm{OH}^{*}}$ is around $1.6 \mathrm{eV}$, the OER overpotential achieves its lowest value (Fig. 3(B)), while the ORR overpotential has its lowest value at $\Delta G_{\mathrm{OOH}^{*}}=4 \mathrm{eV}$ (Fig. $3(\mathrm{C})$ ). These volcano plots enable us to predict the best electrocatalytic properties of the catalysts by considering the reaction free energies only.

Even though the descriptors $\Delta G_{\mathrm{O}^{*}}-\Delta G_{\mathrm{OH}^{*}}$ and $\Delta G_{\mathrm{OOH}^{*}}$ can relate the overpotentials to the adsorption energies of intermediates, it is more desirable for a descriptor to directly correlate the core-shell structures to the activities. To relate the overpotentials to the intrinsic properties of the materials like what Zhao et al. did in their work. ${ }^{37,38}$ We use the strain on shell atoms of plh core-shell metal structure as a descriptor for OER and ORR. The shell strain is defined as, where the denominator is the average bond length of surface $\mathrm{Ag}-\mathrm{Ag}$ in pure $\mathrm{Ag}_{38}$ metal clusters, and the numerator is the average bond length of surface $\mathrm{Ag}-\mathrm{Ag}$ in the core-shell structures. This dimensionless factor successfully relates the activity to the intrinsic structural properties of $\mathrm{Ag}_{32} \mathrm{X}_{6}$ plh core-shell structures. We have plotted the overpotentials of each coreshell structure as a function of the shell strain. As can be seen from Fig. 4(B), the change of shell strain matches the sequence of the $3 \mathrm{~d}$ transition metals in the periodic table. As the atom radius reduces from $\mathrm{Sc}$ to $\mathrm{Cu}$, the shell strain reduces and transforms from tensile to compressive states, and consequently the overpotential becomes smaller successively. The $\mathrm{Ag}_{32} \mathrm{Cu}_{6}$ structure has identified to have the highest compressive strain, yielding the lowest overpotentials. Thus, the overpotentials or catalytic activities can be described well by the shell strain of the clusters.

To further verify the effectiveness of the shell strain in plh core-shell clusters as the descriptor for ORR and OER, we performed another set of calculations on $\mathrm{Cu}_{32} \mathrm{X}_{6}$ structures. These structures are comparable to the $\mathrm{Ag}_{32} \mathrm{X}_{6}$ clusters with the replace of $\mathrm{Ag}$ by $\mathrm{Cu}$. We firstly relaxed the clusters, followed by the self-convergence computations without moving of ions. The Cu core-shell structure also has a unit cell of $20 \AA \times 20 \AA \times 20 \AA$ and the bond length between $\mathrm{Cu}$ and $\mathrm{X}$ is about $2.47 \AA$. Since the $\mathrm{Cu}_{32} \mathrm{Sc}_{6}$ plh core-shell structure is unstable because of too large 

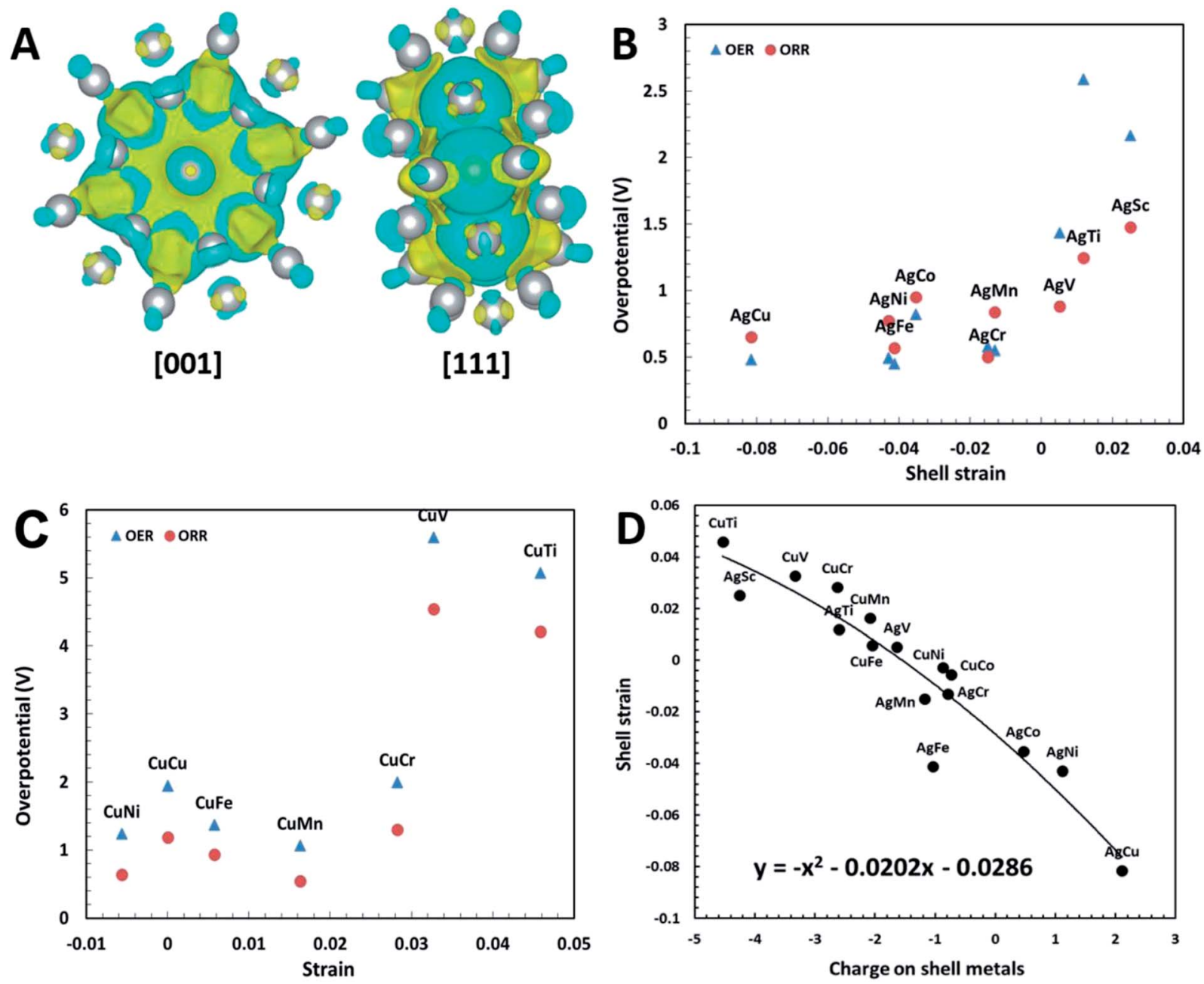

Fig. 4 (A) Charge transfer of $\mathrm{Ag}_{32} \mathrm{Cu}_{6}$ plh core-shell structure. The blue and yellow colors indicate positive and negative charges, respectively. The isosurface level is set to be 0.001 . (B) Relation between ORR/OER overpotentials and shell strain for $\mathrm{Ag}_{32} \mathrm{X}_{6}$ core-shell clusters; (C) relation between ORR/OER overpotential and shell strain for $\mathrm{Cu}_{32} \mathrm{X}_{6}$ core-shell clusters; (D) shell strain of core-shell structure as a function of charges on shell metals $(\mathrm{Ag}, \mathrm{Cu})$. The shell strain follows the equation of the $2^{\text {nd }}$ order polynomial trend line is $y=-x^{2}+0.0202 x-0.0286$, where $x$ is the charges on the shell.

difference in radius between $\mathrm{Cu}$ and $\mathrm{Sc}$, we excluded the analysis of $\mathrm{Cu}_{32} \mathrm{Sc}_{6}$. The free energy diagrams of $\mathrm{Cu}_{32} \mathrm{X}_{6}$ structures for $2 \mathrm{e}$ transfer mechanisms were also plotted in Fig. $\mathrm{S} 4, \dagger$ respectively, and the shell strain of $\mathrm{Cu}_{32} \mathrm{X}_{6}$ is also determined by eqn (1). As shown in Fig. 4(C), the overpotential for $\mathrm{Cu}_{32} \mathrm{X}_{6}$
The excellent catalytic activities of the core-shell structures can be attributed to the charge transfer within the core-shell structures. It was shown for doped-graphene that the charge delocalization facilitated the electrocatalytic reaction. ${ }^{4,40} \mathrm{We}$ have carried out Bader charge transfer analysis ${ }^{34}$ for $\mathrm{Ag}_{32} \mathrm{Cu}_{6} \mathrm{plh}$

$$
\text { Strain }(\text { shell })=\frac{\text { average bond length of surface } \mathrm{Ag}-\mathrm{Ag}(\text { or } \mathrm{Cu}-\mathrm{Cu}) \text { in } \mathrm{Ag}_{32} \mathrm{X}_{6}\left(\text { or } \mathrm{Cu}_{32} \mathrm{X}_{6}\right)}{\text { average bond length of surface } \mathrm{Ag}-\mathrm{Ag}(\text { or } \mathrm{Cu}-\mathrm{Cu}) \text { in pure } \mathrm{Ag}_{38}\left(\text { or } \mathrm{Cu}_{38}\right)}-1
$$

structures reduces with reducing the shell strain, which follows the same trend of the $\mathrm{Ag}_{32} \mathrm{X}_{6}$ clusters. Thus, the shell strain is a general and intrinsic descriptor that is capable of predicting the catalytic activities of the plh core-shell bifunctional catalysts for OER and ORR, and could be extended to other coreshell alloys. core-shell structure (Fig. 4(A)). After the formation of the coreshell structure, the charge transfer occurs on the surface. With the charge redistribution, the core $(\mathrm{Cu})$ carries negative charge while the shell $(\mathrm{Ag})$ becomes positively charged. The positively charged shell $(\mathrm{Ag})$ can easily adsorb intermediates carrying negative charges, which is the essential in ORR and OER. 
According to Zhang et al.'s work, the $\mathrm{O}_{2}$ dissociation energy is $0.715 \mathrm{eV}$ for plh $\mathrm{Ag}_{32} \mathrm{Cu}_{6}$ and the density of states (DOS) at the Fermi energy level is maximal for the favorable absorption site. ${ }^{29}$ Thus, the core-shell-induced charge transfer enhances the electrocatalytic activity of plh $\mathrm{Ag}_{32} \mathrm{Cu}_{6}$.

Similar Bader charge transfer analysis ${ }^{34}$ was also carried out for $\mathrm{Cu}_{32} \mathrm{Ni}_{6}$ structure with the lowest overpotential among all $\mathrm{Cu}_{32} \mathrm{X}_{6}$ clusters. As shown in Fig. $\mathrm{S} 5, \uparrow$ the $\mathrm{Cu}$ shell has positive charges while the Ni core carries negative charges. Similar to $\mathrm{Ag}_{32} \mathrm{Cu}_{6}$ clusters, the positive charges on the shell of the whole structure is believed to enhance the electrochemical activity of the core-shell cluster. However, the amount of the charges transferred in $\mathrm{Cu}_{32} \mathrm{X}_{6}$ is lower than that in $\mathrm{Ag}_{32} \mathrm{X}_{6}$, indicating $\mathrm{Ag}_{32} \mathrm{X}_{6}$ will show better catalytic performance than $\mathrm{Cu}_{32} \mathrm{X}_{6}$. This conclusion is supported by the results in Fig. 4(B) and (C), in which the overpotentials of $\mathrm{Cu}_{32} \mathrm{X}_{6}$ are relatively larger than those of $\mathrm{Ag}_{32} \mathrm{X}_{6}$.

The shell strain of the core-shell cluster is also plotted as a function of charges on shell metals ( $\mathrm{Ag}$ or $\mathrm{Cu}$ ) for $\mathrm{Ag}_{32} \mathrm{X}_{6}$ and $\mathrm{Cu}_{32} \mathrm{X}_{6}$ structures in Fig. 4(D). As the charge on core metals increase, the shell strain also increase with a $2^{\text {nd }}$ order polynomial fitting of $y=-x^{2}+0.0202 x-0.0286$ (round to $y=-x^{2}+$ $x$ ). This demonstrates the charge transfer within the core-shell structures will influence the shell strain. Thus, one effective design strategy to enhance the electrocatalytic activities of plh core-shell metal clusters is to find the core-shell structures with the higher positive charge on shell metals.

\section{Conclusions}

$\mathrm{Ag}_{32} \mathrm{X}_{6}$ and $\mathrm{Cu}_{32} \mathrm{X}_{6}$ plh core-shell structures and their electrocatalytic properties were studied systematically with the DFT methods. The Gibbs free energy, overpotential of OER and ORR on the core-shell structures were calculated to evaluate the electrocatalytic performances. Our results show that $\mathrm{Ag}_{32} \mathrm{Cu}_{6}$ plh core-shell metal clusters exhibit the lowest overpotential comparable to Pt. The shell strain is found to well describe the catalytic activities of the core-shell structures. Increasing the compressive shell strain will induce more positive charge on the shell of the core-shell structures, thus enhancing the adsorption and subsequent reactions on the structures. The design principles developed from the intrinsic descriptor enables the rational design and screening of the core-shell structures for high-performance catalysts by evaluating the strain on the shell.

\section{Conflicts of interest}

There are no conflicts to declare.

\section{Acknowledgements}

This work is supported financially by the National Science Foundation (1561886, 1363123 and 1662288). Computational resources were provided by UNT high performance computing initiative, a project of academic computing and user services within the UNT computing and information technology center.

\section{References}

1 L. Carrette, K. a. Friedrich and U. Stimming, Fuel Cells, 2001, 1, 5-39.

2 J. K. Nørskov, J. Rossmeisl, A. Logadottir, L. Lindqvist, J. R. Kitchin, T. Bligaard and H. Jónsson, J. Phys. Chem. B, 2004, 108, 17886-17892.

3 I. C. Man, H. Y. Su, F. Calle-Vallejo, H. A. Hansen, J. I. Martínez, N. G. Inoglu, J. Kitchin, T. F. Jaramillo, J. K. Nørskov and J. Rossmeisl, ChemCatChem, 2011, 3, 1159-1165.

4 M. Li, L. Zhang, Q. Xu, J. Niu and Z. Xia, J. Catal., 2014, 314, 66-72.

5 J. Zhang, Z. Zhao, Z. Xia and L. Dai, Nat. Nanotechnol., 2015, 10, 444-452.

6 S. Wang, L. Zhang, Z. Xia, A. Roy, D. W. Chang, J.-B. Baek and L. Dai, Angew. Chem., Int. Ed. Engl., 2012, 51, 4209-4212.

7 W. Zhong, W. Tu, S. Feng and A. Xu, J. Alloys Compd., 2019, 772, 669-674.

8 Z. Lin, C. Wang, Z. Wang, Q. Liu, C. Le, B. Lin and S. Chen, Electrochim. Acta, 2019, 294, 142-147.

9 S. Zhou, N. Liu, Z. Wang and J. Zhao, ACS Appl. Mater. Interfaces, 2017, 9, 22578-22587.

10 W. Pei, S. Zhou, Y. Bai and J. Zhao, Carbon, 2018, 133, 260266.

11 X. Xie, M. Wei, L. Du, Y. Nie, X. Qi, Y. Shao and Z. Wei, J. Mater. Chem. A, 2017, 5, 15390-15394.

12 Y. Zhou, Q. Lu, Z. Zhuang, G. S. Hutchings, S. Kattel, Y. Yan, J. G. Chen, J. Q. Xiao and F. Jiao, Adv. Energy Mater., 2015, 5, 1-4.

13 N. Zhang, F. Chen, D. Liu and Z. Xia, ACS Appl. Energy Mater., 2018, 1, 4385-4394.

14 N. Zhang, F. Chen, X. Wu, Q. Wang, A. Qaseem and Z. Xia, J. Mater. Chem. A, 2017, 5, 7043-7054.

15 J. Greeley, I. E. L. Stephens, A. S. Bondarenko, T. P. Johansson, H. A. Hansen, T. F. Jaramillo, J. Rossmeisl, I. Chorkendorff and J. K. Nørskov, Nat. Chem., 2009, 1, 552-556.

16 J. X. Wang, H. Inada, L. Wu, Y. Zhu, Y. Choi, P. Liu, W.-P. Zhou and R. R. Adzic, J. Am. Chem. Soc., 2009, 131, 17298-17302.

17 D. Wang, H. L. Xin, R. Hovden, H. Wang, Y. Yu, D. A. Muller, F. J. DiSalvo and H. D. Abruña, Nat. Mater., 2012, 12, 81-87.

18 L. Gan, M. Heggen, S. Rudi and P. Strasser, Nano Lett., 2012, 12, 5423-5430.

19 A. Qaseem, F. Chen, X. Wu and R. L. Johnston, Catal. Sci. Technol., 2016, 6, 3317-3340.

20 T. Fu, J. Fang, C. Wang and J. Zhao, J. Mater. Chem. A, 2016, 4, 8803-8811.

21 J. A. Bordley and M. A. El-Sayed, J. Phys. Chem. C, 2016, 120, 14643-14651.

22 Y. Chi, L. Zhao, X. Lu, C. An, W. Guo and C. M. L. Wu, J. Mater. Sci., 2016, 51, 1-15.

23 J. Cao, M. Guo, J. Wu, J. Xu, W. Wang and Z. Chen, J. Power Sources, 2015, 277, 155-160. 
24 M. Chatenet, M. Aurousseau, R. Durand and F. Andolfatto, J. Electrochem. Soc., 2003, 150, D47.

25 K. Shin, D. H. Kim and H. M. Lee, ChemSusChem, 2013, 6, 1044-1049.

26 P. Strasser, S. Koh, T. Anniyev, J. Greeley, K. More, C. Yu, Z. Liu, S. Kaya, D. Nordlund, H. Ogasawara, M. F. Toney and A. Nilsson, Nat. Chem., 2010, 2, 454-460.

27 K. Shin, D. H. Kim, S. C. Yeo and H. M. Lee, Catal. Today, 2012, 185, 94-98.

28 H. Jiang, T. Akita, T. Ishida, M. Haruta and Q. Xu, J. Am. Chem. Soc., 2011, 133, 1304-1306.

29 N. Zhang, F. Y. Chen and X. Q. Wu, Sci. Rep., 2015, 5, 1-12.

30 P. E. Blöchl, Phys. Rev. B: Condens. Matter Mater. Phys., 1994, 50, 17953-17979.

31 J. P. Perdew, K. Burke and M. Ernzerhof, D. of Physics and N. O. L. 70118, J. Quantum Theory Group Tulane University, Phys. Rev. Lett., 1996, 77, 3865-3868.

32 A. I. Liechtenstein, V. I. Anisimov and J. Zaanen, Phys. Rev. B: Condens. Matter Mater. Phys., 1995, 52, 5467-5470.
33 H. Dederichs, Phys. Rev. B: Condens. Matter Mater. Phys., 1994, 50, 16861.

34 W. Tang, E. Sanville and G. Henkelman, J. Phys.: Condens. Matter, 2009, 21, 084204.

35 G. Henkelman, A. Arnaldsson and H. Jónsson, Comput. Mater. Sci., 2006, 36, 354-360.

36 Z. Zhao, L. Zhang and Z. Xia, J. Phys. Chem. C, 2016, 120, 2166-2175.

37 Z. Zhao and Z. Xia, ACS Catal., 2016, 1553-1558.

38 Z. Zhao, M. Li, L. Zhang, L. Dai and Z. Xia, Adv. Mater., 2015, 27, 6834-6840.

39 Z. Zhao and Z. Xia, MRS Adv., 2016, 1-5.

40 L. Zhang and Z. Xia, J. Phys. Chem. C, 2011, 115, 1117011176.

41 L. Zhang, J. Niu, M. Li and Z. Xia, J. Phys. Chem. C, 2014, 118, 3545-3553.

42 L. Zhang, J. Niu, L. Dai and Z. Xia, Langmuir, 2012, 28, 75427550 .

43 X. Wu, F. Chen, Y. Jin, N. Zhang and R. L. Johnston, ACS Appl. Mater. Interfaces, 2015, 7, 17782-17791. 